\title{
¿REDES O LÍNEAS DE PESCA? EL PROBLEMA DE LA ASIGNACIÓN MORFOFUNCIONAL DE LOS PESOS LÍTICOS Y SUS IMPLICANCIAS EN LAS TÁCTICAS DE PESCA DE LOS GRUPOS DEL EXTREMO AUSTRAL DE SUDAMÉRICA ${ }^{1}$
}

JIMENA A. TORRES E.

\begin{abstract}
RESUMEN
El presente trabajo tiene como propósito evaluar y potenciar la información que puede entregar el análisis sistemático de artefactos de bajo grado de formatización, como es el caso de los pesos líticos. En Fuego-Patagonia dichos instrumentos han sido hallados en contextos canoeros, tanto tempranos como tardíos, y han sido definidos morfofuncionalmente como pesos de línea de pesca, basándose principalmente en las fuentes etnográficas. Por otro lado, para los grupos cazadores terrestres, se ha reportado etnográficamente el uso de redes para la pesca, no obstante, no se menciona el uso complementario de pesos líticos. La distinción en el registro arqueológico del uso de líneas o redes se dificulta si se considera lo perecedero de la fibra orgánica con que se elaboran, sumado a esto, en otras áreas geográficas artefactos en apariencia similares a los pesos de línea han sido identificados como pesos de redes, pero también como artefactos no vinculados a la pesca. Este trabajo pretende evaluar si se pueden establecer diferencias entre ambos métodos y de esta manera aproximarnos al valor de esta actividad de subsistencia, tanto para canoeros, como para cazadores terrestres.
\end{abstract}

PALABRAS CLAVES: Tecnología de pesca, peso lítico, red, línea de pesca, fueguinos, Tierra del Fuego.

\section{¿NET OR LINE SINKERS? THE PROBLEM OF MORPHO-FUNCTIONAL DISCRIMINATION OF LITHIC SINKERS AND IMPLICATIONS FOR UNDERSTANDINGS OF FISHING TECHNIQUES IN GROUPS OF THE FAR SOUTH OF SOUTH AMERICA}

\footnotetext{
ABSTRACT

In this paper we attempt to assess and expand the information that can be drawn from the systematic analysis of artefacts with a reduced degree of formatization, such as the case of lithic sinkers. In Fuego-Patagonia these artifacts are found in both early and late maritime contexts and have generally been classified as sinkers for line fishing on the basis of morpho-functional and ethnographic criteria. At the same time, the use of fishing nets is reported among ethnographic terrestrial hunter-gatherers but no mention exists for the use of net sinkers. Ascertaining whether archaeological specimens were used as net or line sinkers is made difficult by a lack of preservation of cordage and

1 Proyecto FONDECYT 1020004, "Las ballenas en el mundo selk'nam: un enfoque desde la arqueología y otras disciplinas, en el norte de Tierra del Fuego". Convenio FONDECYT, Dirección de Bibliotecas, Archivos y Museos (Museo de Historia Natural de Concepción) y Universidad de Magallanes (Instituto de la Patagonia).

Licenciada en Antropología, mención Arqueología. Universidad de Chile.
} 
the fact that similar artifacts in other regions have been interpreted both as net sinkers and as artifacts unrelated to fishing activities. In this article we attempt to evaluate if differences can be established between both uses and, in this way, approach their role in the subsistence activities of maritime and terrestrial hunter-gatherers.

KEY WORDS: Fishing Technology, lithic sinker, net fish, line fish, Fuegians, Tierra del Fuego.

\section{INTRODUCCIÓN}

En las ocupaciones litorales continentales e insulares de la Región de Magallanes, tanto de grupos canoeros como cazadores terrestres, se encuentran algunos conjuntos artefactuales de bajo grado de formatización. Éstos muchas veces presentan atributos tecnológicos ambiguos, que no permiten obtener una mayor resolución de su función específica. Muchas veces estas piezas son designadas dentro de una categoría tipológica amplia que engloba grupos como bolas y guijarros piqueteados o astillados. Ya en otros trabajos tanto de contextos canoeros como de cazadores terrestres se ha descrito la presencia de artefactos manufacturados por medio de esta industria (González 1953, Orquera y Piana 1986, Morello 1999, 2000), expresando que bajo la homogeneidad que implica la categoría de guijarros astillados, piqueteados o alisados hay una diversidad de rasgos que podría reflejar requerimientos tecnológicos destinados a propósitos distintos. Por ejemplo, dentro de la categoría yunque, percutor o sobador, pueden haber además otras funciones no identificadas inicialmente. En este sentido, un caso problemático es la categoría de bola que tiene distinciones entre la llamada "bola perdida" y las boleadoras de dos o tres piedras; estas dos últimas, están destinadas a detener o trabar los movimientos de la presa o del enemigo, mientras que la primera, actúa por traumatismo o conmoción al dar en el blanco (González 1953:139). Arqueológicamente, la única manera de distinguir cuando es una bola perdida, es cuando se trata de una bola erizada (González 1953:144). De igual manera, González (Loc. cit.), menciona que también se da la confusión entre las bolas y los pesos de red.

Con relación a esto último, los pesos líticos destinados a la pesca, en primera instancia los diferenciamos de las bolas por no presentar modificaciones en la superficie de la forma base que pudiese estar indicando alguna etapa del proceso de formatización, es decir, trituramiento, alisado por abrasión y pulido (Aschero 1983). En este sentido, la categoría tipológica de peso lítico se ajusta a la descripción hecha por Orquera y Piana, quienes señalan: [Los] "Guijarros con escotaduras piqueteadas:[son] utensilio[s] confeccionado[s] con un canto rodado, un clasto anguloso, una laja $u$ otra forma-base, sobre el que por piqueteamiento se produjeron dos escotaduras o comienzos de un surco en extremos opuestos (o tres o cuatro, espaciados regularmente)" (Orquera y Piana 1986:101). No obstante esta definición al ser una categoría tipológica y no funcional, no contempla explícitamente la diferenciación entre pesos para red o línea de pesca, es decir, la distinción de dos métodos de pesca.

La identificación de dos tácticas de pesca conlleva a considerar una serie de aspectos conductuales. En el caso del uso de redes de pesca, implicaría una alta inversión de energía en la elaboración, mayor cantidad de personas necesarias para su uso, un alto retorno en la captura y las bajas dificultades en su manejo. Por otro lado, las tácticas que incluyan el uso de líneas de pesca, si bien, implicarían menor inversión de energía en su fabricación y requerirían de sólo un sujeto para su utilización; también conllevarían a un menor retorno en la captura y una mayor destreza en su ejecución. Lo que se refiere a la explotación de ambientes costeros intermareales, la pesca con redes es de preferencia en sectores despejados como playas abiertas de sustrato arenoso o de bloques y cantos; en cambio, la línea de pesca puede ser usada tanto en dichos ambientes, como también en sectores rocosos o topografías más irregulares.

Una ventaja metodológica en la identificación de tecnologías de pesca a partir de artefactos expeditivos, es que ante la escasez, preservación diferencial o ausencia de restos de peces en el contexto arqueológico, tanto por agentes naturales como culturales; de todas formas queda representado en el registro la explotación y el consumo de peces y en alguna medida el grado de especialización en las técnicas de pesca. De igual manera, la presencia de 
arpones o anzuelos no sería un requerimiento para inferir el uso de tecnologías especializadas de pesca, ni tampoco para evaluar el grado de intensidad de estas prácticas y su importancia.

En síntesis, el presente trabajo tiene como finalidad aproximarnos a las potencialidades del estudio de artefactos de bajo valor diagnóstico e identificar en el registro arqueológico evidencias de actividad de pesca. Sobre la base de estos resultados, se pretende evaluar la factibilidad de la generación de indicadores para discriminar entre el uso de redes o líneas de pesca.

\section{ANTECEDENTES}

Referencias del uso de redes y líneas de pesca en el área de estudio

En cuanto a los antecedentes del área de estudio, el uso de pesas para líneas de pesca se reporta para adaptaciones marítimas tardías, como los grupos yámana (Lothrop 1928, Orquera y Piana 1999a, Bridges 2000). La información arqueológica incluye contextos del norte del canal Beagle y del sector del estrecho de Magallanes. En los sitios del canal Beagle, desde momentos tempranos se han hallado guijarros con surcos piqueteados o con extracción de muescas, como en el segundo componente de Túnel I (Orquera y Piana 1999b) y en la unidad inferior de Imiwaia I (Orquera y Piana, 1999b, 2000). Se destaca que en ambos sitios son abundantes los instrumentos de piedra piqueteada, y también los restos ictiológicos. En el segundo componente del sitio Túnel I, los restos de peces son más abundantes en comparación a los otros componentes, y en el caso de Imiwaia I, la concentración es aún mucho mayor que en el contexto anterior (Orquera y Piana 1999b, Zangrando 2003). En cuanto a los sitios tardíos, el sitio Lanashuahia también presenta guijarros con escotadura piqueteada, escotadura tallada y con surco piqueteado (Piana et al. 2000).

Más hacia el norte, en la península de Brunswick, estrecho de Magallanes, se encontraron artefactos muy similares en los sitios de canoeros tempranos de punta Santa Ana 1 y Bahía Buena 1, excavados por Ortiz-Troncoso (1973, 1975, 1978) (Fig. 1). Este investigador clasificó estas piezas dentro de la categoría de piedra martillada o pulida, donde los rodados, generalmente elípticos con dos escotaduras en sus extremos, son más abundantes (Ortiz-Troncoso 1975). El autor si bien, se refiere a estos hallazgos como presumiblemente para lastrar líneas de pesca, también advierte que en el sitio de la isla Englefield se hallaron similares artefactos los cuales fueron identificados como "...pesos para redes de una población viviendo esencialmente de la pesca..." (Emperaire y Laming 1961:30). A esto se suman los hallazgos de piezas de similares características en el sitio de Bahía Colorada, también en la isla Englefield (Legoupil 1997). No obstante, Ortiz-Troncoso señala: “...Sin embargo no parece que los fueguinos de los archipiélagos hayan, en los tiempos históricos, practicado la pesca con redes" (1975:108). Si bien, en momentos históricos no fue reportado el uso de redes por los grupos canoeros, no debe descartarse que pudo ser una práctica en momentos prehistóricos. No obstante, se debe considerar que hay planteamientos sobre una continuidad adaptativa y tecnológica de los grupos canoeros desde el período temprano a momentos tardíos (Orquera y Piana 1999b), y si se considera este punto, las descripciones etnográficas que señalan el uso de líneas de pesca podrían extrapolarse parcialmente a las prácticas de los canoeros tempranos de la zona del estrecho de Magallanes, como ya se ha hecho en las investigaciones en el norte del canal Beagle. En este sentido, el trabajo de M. Álvarez compara las estrategias tecnológicas desarrolladas por canoeros tempranos de distintos sectores del área fuego-patagónica, estableciendo un ordenamiento de los conjuntos líticos en tres grupos tecno-morfológicos (Álvarez 2004). En el grupo II, incluye las piezas manufacturadas sobre guijarros y fragmentos de roca formatizados por piqueteamiento o alisamiento. Dentro de este grupo se incluyen los guijarros con escotadura tallada, piqueteada o con surco, que corresponderían a posibles pesos de línea. En su estudio establece un alto grado de similitud en la estructura de los conjuntos y la técnica de manufactura de los distintos conjuntos analizados.

Hay referencias etnográficas de los grupos yámana sobre el uso de líneas de pesca asociadas a pesos líticos, por parte. Bridges señala que una táctica propia de las mujeres, era el uso de sedales hechos de su propio cabello trenzado, y cerca de la carnada ataban a la caña una piedra perfectamente redondeada con una pequeña ranura hecha ex 


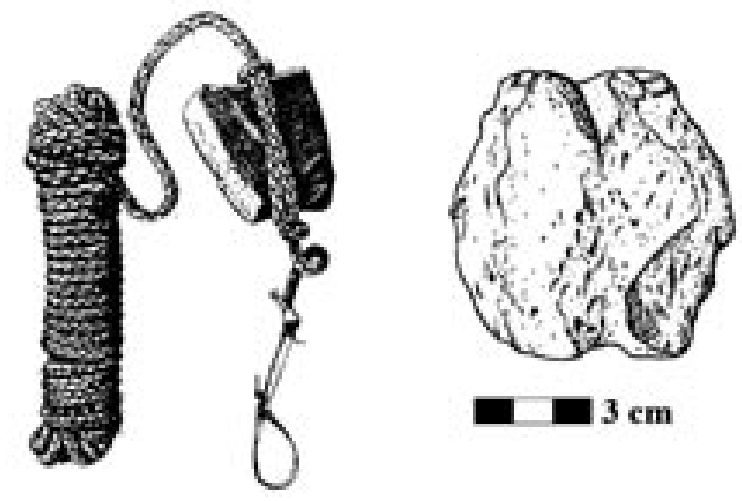

Fig. 1. A la izquierda: línea de pesca yámana (Lothrop 1928). A la derecha: pieza del sitio

Punta Santa Ana 1 (Ortiz-Troncoso 1975).

profeso para sujetar la línea (2000:94). Además, menciona no haber visto nunca a los indígenas elaborar este tipo de piedras, ni escuchó decir que las hicieran en nuestra época, por lo que piensa que probablemente anteriores generaciones de nativos pudieron haberlas dejado en tal cantidad en las chozas abandonadas, que resultaba innecesario el enorme trabajo de tallar nuevas piedras (Bridges 2000:94-95). Por otro lado, en otras fuentes se describen atributos técnicos de estas piezas con relación a su morfología, señalando que la piedra debe ser perfectamente redonda para hundirla con rapidez (Spears, 1895:61, en Orquera y Piana 1999a). Otra condición tecnológica tiene relación con el tamaño del peso, el cual varía de acuerdo al tipo de línea utilizada, es decir, si es de cochayuyo o de tendones trenzados; para esta última técnica se usaban guijarros con mayor peso que para la primera. En cuanto a la modificación realizada para su amarre se menciona la realización de dos escotaduras apicales (Lothrop 1928:159, Gusinde 1937: 473 y 530), lo que también se puede observar en una pieza recuperada por la misión científica del Cabo de Hornos depositada actualmente en la colección del Museo del Hombre de París (Prieto y Cárdenas 2002). Ésta, muestra una larga trenza de tendones amarrada en torno a una piedra ovalada muy redondeada y con ranuras para sujetar la trenza en la parte más larga de la pieza (Op cit.). Pese a que las descripciones por lo general concuerdan con la utilización de formas redondeadas, Lothrop (1928) muestra una línea de pesca con un peso de forma cuadrangular, de sección plana y con un surco donde se sujeta el amarre, lo que da cuenta de las variaciones tipológicas entre los pesos descritos, tanto por su tamaño, como por su forma (Fig. 1).

En contraste a la información etnográfica y arqueológica disponible sobre los grupos canoeros de la región, para los grupos cazadores terrestres de Tierra del Fuego existe escasa información referente al uso de este método de pesca, tanto desde la evidencia arqueológica como desde la información etnográfica. Las observaciones realizadas sobre algunos grupos selk'nam del norte de Tierra del Fuego señalan la utilización de técnicas de pesca individuales, como la caña o el cebo (Gallardo 1998:203). Puntualmente, se menciona que algunos indígenas en diversas bahías y lagunas del norte de Tierra del Fuego la utilizaban (Gusinde 1982:266). No obstante, no se hace mención del uso de un peso para esta técnica.

Por otro lado, existen referencias sobre la ejecución de redes y a diferencia de las líneas de pesca, la utilización de esta tecnología es prácticamente exclusiva de los grupos selk'nam y haush; puesto que no hay referencias de su uso en grupos canoeros. Incluso se señala que los últimos alacalufes (kawésqar) no recuerdan haber sabido o visto el uso de esta tecnología en tiempos pasados (Emperaire 1963:182). En cuanto al tipo de red utilizada por los selk'nam, Gallardo (1998:204) señala que la confección de las redes era muy similar a la que utilizan los occidentales, incluso con el mismo nudo. El material para su confección son los tendones de guanaco (Coiazzi 1997:54, Gallardo 1998:204, Chapman 1989:142, Schindler 1995:184), y también las barbas de ballena (Chapman 1989). Se desprende de la información etnográfica que la elaboración, al parecer, requería de mucho trabajo e insumos -como tendones-, razón por la cual había muy pocos ejemplares de redes, prefiriéndose barreras de ramas para obstaculizar la huida de los peces al mar. Los tendones recién sacados son de unos $50 \mathrm{~cm}$. Éstos se pueden subdividir sacando muchos hilos de cada uno, los que eran torcidos para hacer una piola. Al parecer el tamaño de las redes era variable y dependiendo de este factor era la cantidad de hombres que se necesitaba para maniobrarla (Tabla 1). Por su parte, Lista menciona que los onas de bahía Thetis usaban unas pequeñas redes hechas de nervio de guanaco, sin especificar dónde se usan (río-lagunas-mar) ni cómo se manio- 
Tabla 1. Datos métricos de redes selk'nam.

\begin{tabular}{cccc}
\hline Largo & Ancho $\begin{array}{c}\mathrm{N}^{\circ} \text { de } \\
\text { hombres }\end{array}$ & Referencias \\
\hline $3 \mathrm{~m}$ arriba y $2,4 \mathrm{~m}$ abajo & $0,55 \mathrm{~m}$ & & Prieto (2004) \\
$1,5 \mathrm{~m}$ & $0,8 \mathrm{~m}$ & & Prieto (2004) \\
$2 \mathrm{~m}$ & $1 \mathrm{~m}$ & 2 & Coiazzi (1914) \\
$10 \mathrm{~m}$ & $1,5 \mathrm{~m}$ & 6 a 10 & Gallardo (1910) \\
\hline
\end{tabular}

bran (1998:98). Este dato puede corresponder a los grupos denominados haush, ya que esta bahía está dentro de sus límites geográficos (Lanata 1996). Lo anterior, sumado a la información que entrega Schindler (1995:184), sobre el uso por parte los haush de redes de pesca en el mar; suma argumentos tecno-económicos que vinculan culturalmente a los selk'nam con los haush, dicha postura es adoptada por algunos autores (Gusinde 1982, Chapman 1982, Coiazzi 1997).

Por su parte, en una descripción cualitativa y métrica que se realizó de una red selk'nam que se encuentra en el Museo Salesiano Maggiorino Borgatello, se menciona la presencia de una lonja de cuero menos elástica y más firme que las otras cuerdas de la malla, que podría dar indicios del uso de algún elemento como pesos; sin embargo, también puede haber tenido como función reforzar el lado de la red más expuesto al desgaste por fricción y peso (Prieto 2004). Por el momento la única evidencia arqueológica indirecta que puede indicar el uso de redes, es la presencia de guijarros con muescas y semisurcos laterales en contextos litorales de cazadores terrestres del norte de Tierra del Fuego (Massone y Torres 2004).

Por otro lado, existen antecedentes sobre la presencia esporádica de grupos kawésqar en el litoral de bahía Inútil y que pudieron estar en contacto con los grupos selk'nam de este sector (Emperaire 1963:64). De esta situación de interacción se desprende la generación de contextos arqueológicos canoeros en las proximidades de territorios de cazadores terrestres de Tierra del Fuego, como ya se ha sugerido en trabajos en el área de puerto Arturo, al sur de bahía Inútil (Ocampo y Rivas 1996). De tal manera, considerando la profundidad temporal del uso de líneas de pesca por parte de los grupos canoeros y el uso de redes por los grupos cazadores terrestres en momentos tardíos, se hace necesario generar métodos para diferenciar ambas técnicas de pesca.
Antecedentes complementarios sobre el uso de redes y líneas de pesca en otras áreas

En otras áreas de investigación, también se dan estos problemas en la asignación morfofuncional de piezas que aparentan ser pesos de línea; el problema se agudiza si se considera que dentro de una misma categoría denominada "plummets" se encuentran artefactos asociados a la pesca (como pesos para redes, o líneas con y sin anzuelo), a la guerra o a la caza, a elemento de poder traumático (boleadora); al trabajo textil (como torteras), a un elemento simplemente decorativo o de ornamentación (amuleto o pendiente); o a un elemento con una función ritual (Pennypaker 1938). De todas maneras hay que tomar en cuenta que muchos de estos ejemplares son bastante más elaborados y algunos de un trabajo más detallado y minucioso que los que se encuentran en la presente área de estudio; esto conlleva, en el primer caso, a tener más dificultades en la definición de su función.

En los casos que se han determinado morfofuncionalmente como pesos para la pesca, por ejemplo, en las colecciones de artefactos recuperadas en lagos al oeste de Nevada (Tuohy 1968), en la costa de California (Henshaw 1885) o en otros estados de Estados Unidos y Canadá (Pennypaker 1938), los autores coinciden en las ambigüedades al momento de determinar la función de estas piezas. Pese a esta incertidumbre, se puede tener claridad que en todos los casos las piezas se han encontrado en sectores próximos a la costa o en lagos, por lo que puede haber cierta relación entre este tipo de ambientes y el uso de un determinado tipo de instrumento. Sumado a esto, en todos los casos se menciona que el uso más probable de este artefacto fue para línea de pesca, incluso, un autor las compara con las piezas encontradas en los contextos eskimo (Pennypaker 1938). Ligado a esto también pueden ser observadas en las composiciones ergológicas de los grupos Aleutian, las que incluyen guijarros con muescas en los extremos y guijarros con surco transversal o en un extremo de la pieza (Bank 1953).

En cuanto a las alusiones sobre la presencia de pesos para líneas de pesca, si bien muchas de las piezas mencionadas en estos trabajos son bastante diferentes entre sí y se alejan aún más en apariencia con las encontradas en Fuego-Patagonia, se pueden 
extraer atributos tecnológicos aplicables a artefactos con funcionalidad similar. De estos trabajos y bajo el supuesto que las piezas corresponden a pesas de línea, se desprende que todas las observaciones indican una morfología tendiente a ovalada, tubular, alargada o cónica. Lo destacable es que pese a presentar formas disímiles, a exhibir distintos niveles de elaboración y a mostrar una amplia variedad de diseños y decoración dependiendo del contexto cultural y período del cual provenga, la ubicación del surco o muesca para el amarre de la línea siempre se encuentra en el eje mayor de la pieza y por lo general, la sección de las piezas tiende a ser más biconvexa que aplanada, no obstante hay excepciones como piezas más esferoidales y con surco transversal (Bank 1953).

Respecto a las referencias sobre el uso de redes de pesca y pesos asociados, son escasas las descripciones que indiquen mejor los atributos tecnológicos de los pesos para redes. Se ha señalado la utilización de redes en ambientes litorales y lacustres, y que el uso de pesos es indispensable para mantener la capa de las mallas en posición vertical, necesitando alrededor de 3 a 5 kilos de peso para $100 \mathrm{~m}$ de red. El tipo de peso más comúnmente encontrado, es el guijarro con muescas de un tamaño variable de 5 a $15 \mathrm{~cm}$ y de un peso de 20 a 200 gramos. El amarre es obtenido por una muesca doble en el borde lateral o algunas grandes extracciones bifaces (Cleyet-Merle 1990) (Fig. 2). En contextos lacustres, se han encontrado guijarros con extracciones o muescas laterales interpretados como pesos de red (Greenspan 1998). Éstos fueron localizados en rasgos que contenían una concentración de estas piezas, lo cual fue interpretado como un sector donde se descartó o abandonó la red y eventualmente se descompuso, preservándose sólo los pesos de piedra (Greenspan 1998). Ligado a esto, se desprende que las pesas de red deberían encontrarse en algunos casos concentradas, ya que se necesitarían varias piezas para el uso de esta técnica, en cambio, las pesas de línea pueden hallarse en forma individual en los contextos, tanto por abandono, como por extravío durante su uso.

Con relación a lo anterior, en sitios de grupos cazadores recolectores del Holoceno Medio-Tardío en la zona centro sur de Chile, hay concentraciones de abundantes guijarros aplanados con muescas laterales, algunos pequeños y livianos, y otros más

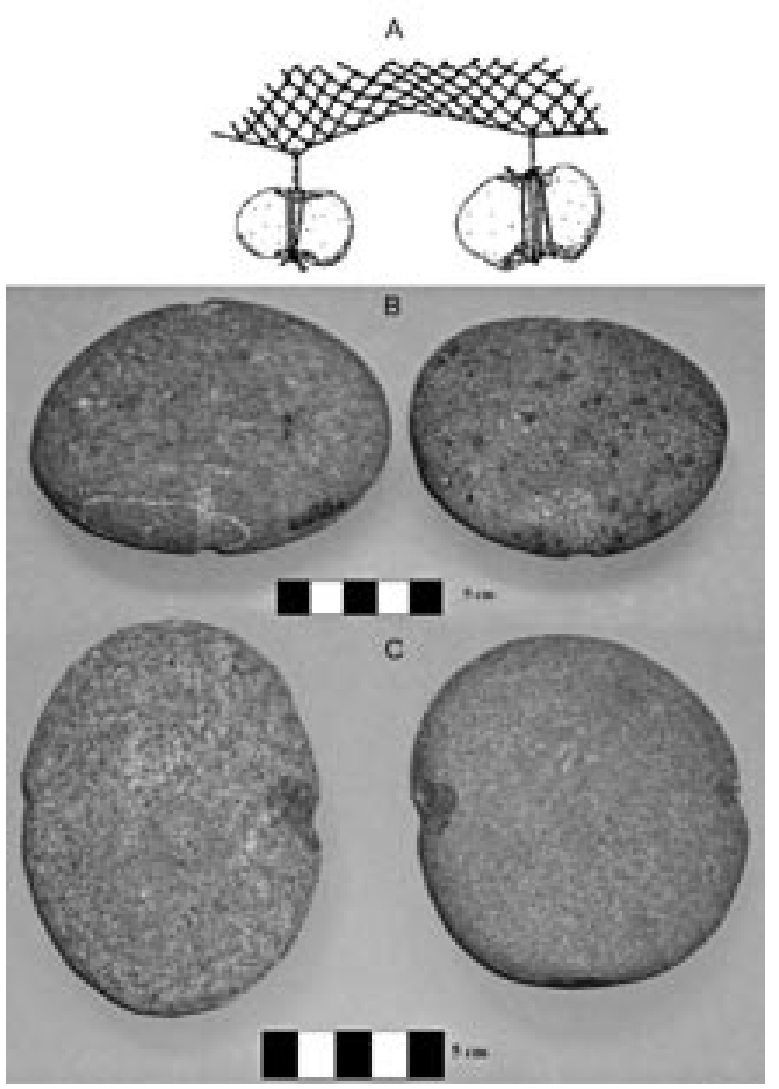

Fig. 2. A): Representación de red con pesas líticas (Cleyet-Merle 1990). B): Piezas con semisurco lateral, sitio Punta Catalina 3. C): Piezas con muescas laterales, sitio Punta Catalina 3.

grandes y pesados (Contreras y Jackson 2004, Quiroz et al. 2001, Bustos y Vergara 1998, Seguel 1998). También, pero en menor medida, aparecen guijarros con muescas en el eje mayor o surcos longitudinales, pero siempre en menor frecuencia que los con muescas laterales. En cuanto a la funcionalidad, estas piezas fueron posiblemente utilizadas para redes (Torres et al. 2007). El sitio Talcahuano 1 de la misma zona, presenta piezas de un tamaño y peso mayor a las de los otros sitios, además de encontrarse agrupadas en un sector restringido (Bustos y Vergara 1998).

En el caso de los pesos de red, el factor peso y tamaño puede variar dependiendo del tipo de red, incluso, en una misma red pueden haber pesos diferentes, unos para dejarla vertical y otros para anclarla en los extremos. En cambio en el caso de los pesos de línea, estos factores sí pueden incidir 
Tabla 2. Cuadro comparativo de los datos sobre líneas y redes de pesca según sus atributos tecnológicos.

\begin{tabular}{|c|c|c|c|}
\hline & \multicolumn{2}{|c|}{ Pesos de línea } & Pesos de red \\
\hline Variable & Yámana & Otras áreas & Otras áreas \\
\hline Referencias & $\begin{array}{l}\text { Bridges 1947, Orquera y } \\
\text { Piana 1999a, 2000; Piana et } \\
\text { al. 2000, Lothrop } 1928 .\end{array}$ & $\begin{array}{l}\text { Pennypaker 1938, Henshaw } 1885 \\
\text { Tuohy 1968, Bank } 1953 .\end{array}$ & $\begin{array}{l}\text { Greenspan 1998, Contreras } \\
\text { y Jackson 2004, Quiroz et } \\
\text { al. 2001, Bustos y Vergara } \\
\text { 1998, Seguel 1998. }\end{array}$ \\
\hline Forma & Redondeada & \begin{tabular}{|l|} 
Son variadas, ovalada, alargada o por lo \\
general el extremo distal más adelgazado
\end{tabular} & Alargadas, ovoidales \\
\hline Contexto & $\ldots \ldots$ & Hallazgos aislados & Concentraciones \\
\hline Tamaño & $\begin{array}{l}\text { Varía de acuerdo al } \\
\text { material de la línea }\end{array}$ & Variable & Variable \\
\hline Sección & Biconvexa & Biconvexa & Aplanadas \\
\hline $\begin{array}{l}\text { Lugar de } \\
\text { modificaciones }\end{array}$ & En el eje longitudinal & $\begin{array}{l}\text { En el eje longitudinal, en uno } \\
\text { o ambos extremos. } \\
\text { En piezas pequeñas y semiesféricas } \\
\text { c/ surcoecuatorial }\end{array}$ & Eje transversal \\
\hline $\begin{array}{l}\text { Tipo de } \\
\text { modificaciones }\end{array}$ & $\begin{array}{l}\text { Surco longitudinal o } \\
\text { escotaduras en los extremos }\end{array}$ & $\begin{array}{l}\text { Muescas, surco perimetral en un extremo, } \\
\text { semi-surco o surco longitudinal. }\end{array}$ & Muescas \\
\hline Peso & $\begin{array}{l}\text { Variada de acuerdo } \\
\text { al material de la línea } \\
\text { (cochayuyo o tendón) }\end{array}$ & Variable & Variable \\
\hline
\end{tabular}

en el uso de la línea, debido a los requerimientos técnicos en su uso. Por otro lado, la ubicación de la modificación para el amarre y la morfología de la pieza pudieron ser atributos más decisivos para ambos métodos. En síntesis, algunas expectativas que podrían darse en piezas identificadas como pesos de red y de líneas de pesca se resumen en la Tabla 2.

\section{MATERIALES Y MÉTODO}

Con el propósito de evaluar la asignación funcional de las piezas designadas como pesos de red o de líneas de pesca, se ha contemplado una muestra de contextos del litoral de Tierra del Fuego de filiación cazador recolector terrestre, y un conjunto de referencia que proviene de ocupaciones litorales continentales e insulares de grupos de adaptación marina (Fig. 3). Se examinó un total de 80 guijarros o fragmentos de roca con modificaciones (Tabla 3). El interés principal es caracterizar morfofuncionalmente los pesos líticos de las ocupaciones de cazadores terrestres, por lo que la muestra de mayor tamaño corresponde a estos contextos; la muestra proveniente de ocupaciones canoeras es significativamente más limitada en tamaño y tiene como objetivo ser una referencia comparativa y no el objeto de estudio principal del trabajo.

El conjunto de bahía Inútil en Tierra del Fuego está conformado por:
Marazzi 32 (MA-32), localizado en bahía Inútil sobre una berma litoral de guijarros, a $70 \mathrm{~m}$ de la línea de alta marea y sólo a un par de metros del río Marazzi (Massone et al. 2003, Massone y Morello 2005). La muestra es sólo una pieza que proviene de una intervención estratigráfica (unidad $16 \mathrm{D}$ ) donde apareció abundante material ictioarqueológico (Torres 2005). El conjunto más grande es de Marazzi 30 (MA-30), se ubica sobre una paleoberma a $250 \mathrm{~m}$ de distancia de la costa actual y a $100 \mathrm{~m}$ del sitio MA-32. Es una dispersión superficial y restringida de pesas, con una superficie de $250 \mathrm{~m}^{2}$ y se asocia sólo un percutor. Los ejem-

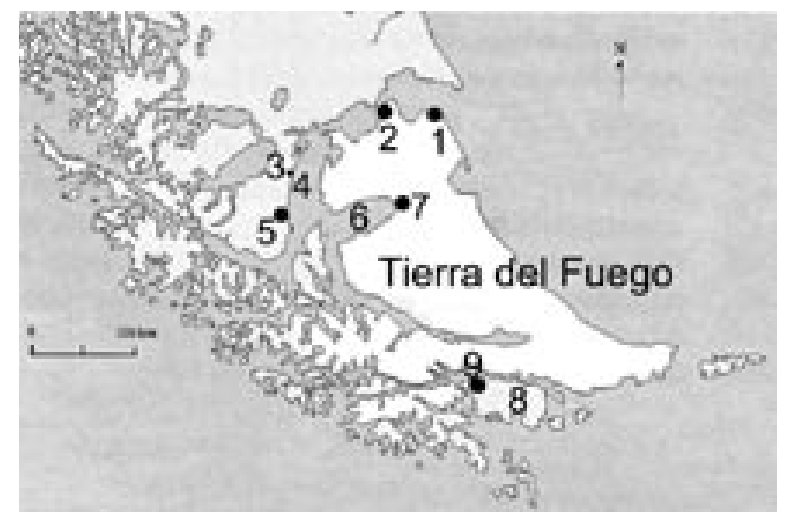

Fig. 3. Área de estudio. 1): sitio Punta Catalina3; 2): sitio Punta Baxa-7; 3): Ciudad de Punta Arenas; 4): estrecho de Magallanes; 5): sitio Bahía Buena-1; 6): bahía Inútil; 7): sitios de la localidad de Marazzi; 8): isla Navarino; 9): sitio Wulaia-15. 
Tabla 3. Contexto de las muestras analizadas del norte de Tierra del Fuego y muestra de referencia de grupos canoeros.

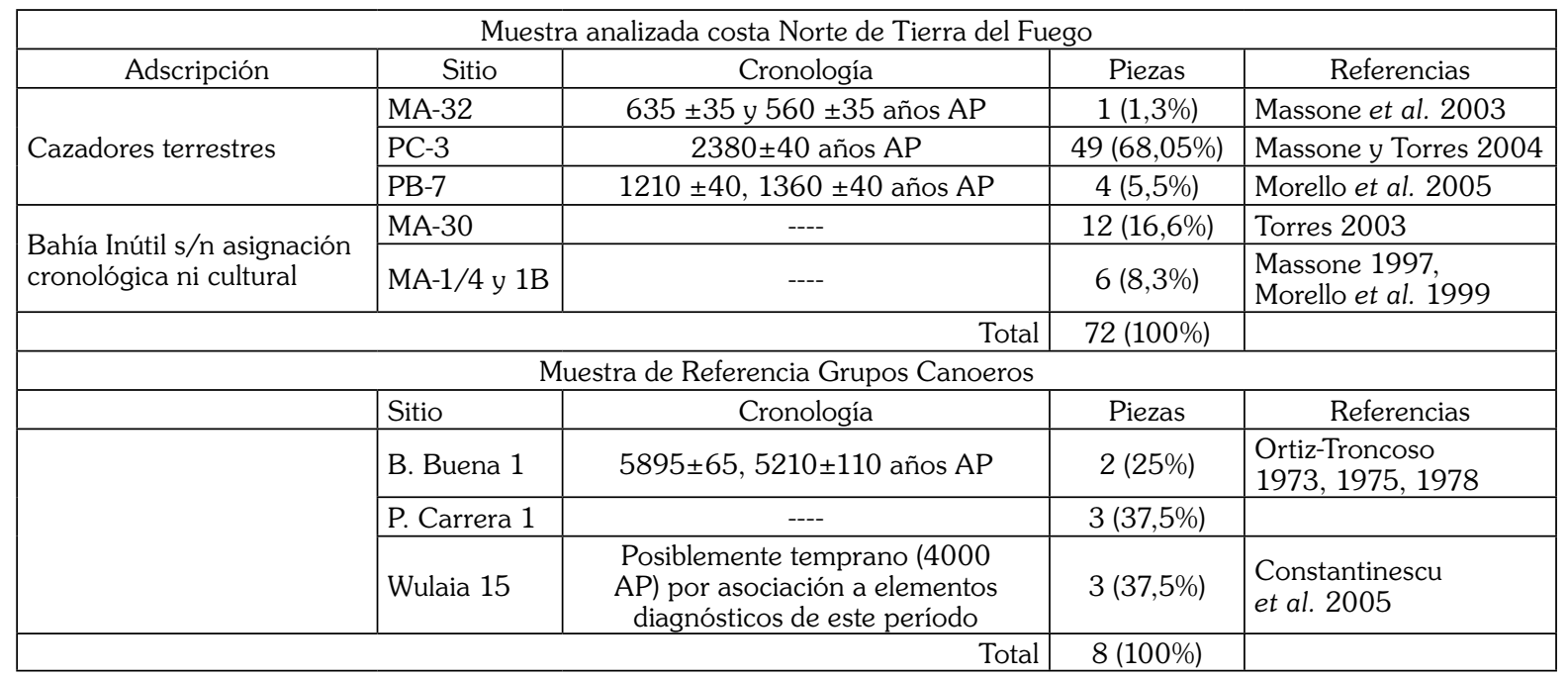

plares se registraron in situ y se consideraron todas las piezas del contexto. Por otro lado, Marazzi 1B o $\mathrm{K}$ (MA-1B) corresponde también a una dispersión superficial de materiales inmersa en una zona con varios sitios que forman un continuo de materiales, se encuentra $100 \mathrm{~m}$ al oeste del bloque Marazzi 1 (Massone 1997, Morello et al. 1999). Vinculado a esta dispersión se encuentra Marazzi 1 sector 4 (MA1/4) considerado parte de este continuo (Massone 1997). Las piezas de ambos contextos provienen de una recolección selectiva.

En cuanto a los sitios del noreste de Tierra del Fuego, se encuentra Punta Baxa 7 (PB-7), ubicado en el extremo oriental de bahía Felipe en Primera Angostura. Es un extenso sitio ubicado sobre la barranca en una zona de dunas. Está constituido por conchales, concentraciones de restos óseos y talleres líticos (Morello et al. 2005). Las piezas fueron recuperadas de una intervención estratigráfica (dunas sur/sector 2), recolección relativa. Por último, la muestra más grande proviene de Punta Catalina 3 (PC-3), un extenso sitio constituido por conchales, concentraciones de restos óseos y talleres líticos; se encuentra en un sistema de dunas deflacionadas próximo a la línea de costa (Massone y Torres 2004). Los materiales provienen de una recolección sistemática (unidades 1-2-3-4-5-6) y de una intervención estratigráfica (unidad 6).

En cuanto a la adscripción cultural de estos contextos, Punta Catalina 3, Punta Baxa 7 y Marazzi 32, presentan elementos diagnósticos de filiación de cazadores terrestres, como epífisis de guanaco con corte perimetral, hasta el momento estos artefactos no han sido reportados en contextos canoeros. De igual modo las piezas terminadas de boleadora, las preformas y los desechos de gabro en los sitios Punta Baxa 7, Marazzi 1/sector 4, Marazzi 1B o K y Punta Catalina 3, vinculan estos eventos ocupacionales a poblaciones de cazadores terrestres. En el caso de Marazzi 30, no hay evidencias que indiquen su filiación.

Respecto a la muestra procedente de contextos canoeros, es bastante más reducida que la anterior. Estos están constituidos por los sitios ubicados al norte del estrecho de Magallanes; como el sitio Bahía Buena 1, ubicado en Península de Brunswick. Las piezas analizadas fueron recuperadas en una excavación sistemática, y es una parte pequeña de todas las pesas registradas inicialmente (OrtizTroncoso 1973, 1975, 1978). Otro contexto es Punta Carrera 1, localizado $52 \mathrm{~km}$ al sur de Punta Arenas; los materiales fueron recuperados a partir de labores de salvataje arqueológico (com. pers. San Román 2005)². Por último, está la muestra procedente de contextos insulares representada por el sitio Wulaia 15, localizado en la bahía homónima en isla Navarino; los materiales provienen de una intervención estratigráfica (sondeo 4) (Constantinescu et al. 2005).

2 Desarrolladas por el Centro de Estudios del Hombre Austral del Instituto de la Patagonia, durante los años 2003-2004. 
Se analizaron cada una de las piezas que presentasen propiedades morfofuncionales de pesas. Los atributos que las definen como pesas líticas, son las modificaciones en forma de muesca o surco, hechas sobre el eje mayor o menor (o ambos ejes) de un fragmento de roca o un guijarro, probablemente con la función de retener un amarre.

Las variables consideradas incluyen aspectos cualitativos que pudieron influir en la selección de las matrices y su uso específico; como tipo de matriz, morfología general (ovoidal, circular, alargada, irregular, cuadrangular), sección transversal y longitudinal, y materia prima. Por otro lado, se consideró técnica de modificación empleada (piqueteado, extracción, pulimento), intensidad (insinuado, marcado o profundo), tipo de modificación (surco, semi-surco, muesca por piqueteado, extracción o ambas). Por último se estimó el largo, ancho, espesor y peso de las piezas. En vista que el análisis de MA-30 y MA-1/4 se realizó in situ, no se pudo estimar su peso.

Se consideraron 5 categorías de análisis que combinan técnica y tipo de modificación empleada:

1.- Muescas logradas por extracciones o tallado (percusión): Se distingue el negativo de la extracción en algunas piezas y es muy marcado.

2.- Muescas por piqueteado o trituramiento: Se diferencian de las muescas por extracción porque tienen una hendidura menos pronunciada y más irregular o áspera, propio de un machacado.

3.- Muesca por técnica mixta: Se alternan los dos tipos de modificaciones anteriores, una en cada lado o extremo, o sobre el mismo lugar.

4.- Semisurcos: Obtenidos probablemente por el raspado y piqueteado de la parte media de la pieza en ambos lados o extremos. Es una hendidura más estrecha que las anteriores. No se extiende por todo el diámetro de la pieza, se delimita sólo a los lados o extremos.

5.- Surco completo: Se aplica la misma técnica anterior, no obstante, continúa a lo largo de todo el contorno de la pieza ya sea longitudinal o transversalmente.

\section{RESULTADOS}

\section{A.- Costa noreste de Tierra del Fuego}

\section{Punta Baxa 7 (PB-7)}

Estos ejemplares, al igual que de Punta Catalina 3, fueron encontrados en contextos superficiales y estratigráficos. 3 de las 4 piezas fueron halladas en estratigrafía y asociadas a restos ictioarqueológicos.

Las 4 piezas son guijarros de granito, de sección biconvexa y con la modificación o hendiduras en el eje menor. Las pesas halladas en estratigrafía se encontraron en las dunas sur 1 , sector 2 , estrato IV; 2 de éstas presentan semisurcos laterales profundos por piqueteado y 1 presenta muescas laterales sólo insinuadas. Por último, se encuentra la pieza de recolección superficial, que consiste en un guijarro de granito compacto y exhibe un surco piqueteado muy marcado casi completo alrededor. El largo, el ancho y el peso de las piezas es bastante inferior al de los ejemplares de PC-3, no obstante, el espesor se mantiene similar, de lo que resulta piezas más globulares que aplanadas y alargadas (Tabla 4).

\section{Punta Catalina 3 (PC-3)}

Constituye la muestra más grande del conjunto con el 68,05\%. Una parte de ésta fue recuperada de un basural conchífero a partir de una recolección superficial en 2 unidades adosadas de $4 \mathrm{~m}^{2}$ cada una (C5 y C6), y de una intervención estratigráfica de una de éstas. El otro conjunto fue recuperado en una recolección sistemática en 4 unidades adosadas de $4 \mathrm{~m}^{2}$ cada una (C1-C2-C3 y C4), en un sector distanciado del conchal (noreste del sitio) (Massone y Torres 2004).

Tabla 4. Promedio y desviación estándar de los atributos métricos de las piezas de los sitios de Tierra del Fuego.

\begin{tabular}{lllllllllrr}
\hline & \multicolumn{3}{c}{ Largo $(\mathrm{cm})$} & \multicolumn{3}{c}{ Ancho $(\mathrm{cm})$} & \multicolumn{3}{c}{ Espesor (cm) } \\
\cline { 2 - 10 } & \multicolumn{1}{c}{ B. Inútil } & PC-3 & PB-7 & B. Inútil & PC-3 & PB-7 & B. Inútil & PC-3 & PB-7 \\
\cline { 2 - 10 } X: & 11,35 & 11,43 & 6,72 & 8,64 & 9,47 & 5,7 & 5,08 & 3,43 & 3,51 \\
ds (1): & 1,83 & 1,304 & 1,01 & 1,3 & 1,04 & 0,42 & 1,06 & 0,77 & 0,25 \\
ds (2): & 1,80 & 1,296 & 2,65 & 1,28 & 1,04 & 0,39 & 1,05 & 0,77 & 1,05 \\
\hline
\end{tabular}


Tabla 5. Frecuencia absoluta y relativa de pesas según su funcionalidad o multifuncionalidad, en el sector del conchal y sector noreste de PC-3.

\begin{tabular}{|c|c|c|c|c|}
\hline \multirow{2}{*}{$\frac{\text { PC-3 }}{\text { función }}$} & \multicolumn{2}{|c|}{ sector conchal } & \multicolumn{2}{|c|}{ sector noreste } \\
\hline & $\mathrm{N}^{\circ}$ de piezas & $\%$ & $\mathrm{~N}^{\circ}$ de piezas & $\%$ \\
\hline Pesa & 7 & 58,33 & 32 & 88,88 \\
\hline Pesa/percutor & 3 & 25 & 1 & 2,77 \\
\hline Pesa/yunque & 1 & 8,33 & 2 & 5,55 \\
\hline Pesa/yunque/percutor & 1 & 8,33 & --- & --- \\
\hline Yunque, percutor, sobador, pesa & --- & --- & 1 & 2,77 \\
\hline $\begin{array}{r}\text { TOTAL } \\
\end{array}$ & 12 & 100 & 36 & 100 \\
\hline
\end{tabular}

49 piezas fueron identificadas morfofuncionalmente como pesos líticos, no obstante, en algunos casos se le suman rasgos asociados a funciones anexas, como percutores, sobadores o yunques. En cuanto a las técnicas y tipos de modificación del sector de amarre, se identificaron cuatro técnicas, $y$ en todos los casos se localizaron en el eje menor (transversal) del ejemplar.

En los dos sectores se observan atributos similares en las piezas. En ambos se observa un predominio del uso específico como pesas y un segmento menor fue definido como multifuncionales (Tabla 5). Una sola pieza fue hallada en estratigrafía (C6/20-30 cm) y corresponde a una pesa/percutor. La reutilización de pesas para otras actividades $\mathrm{o}$, a la inversa, el uso de percutores, yunques o sobadores como pesas; es una conducta aparentemente innecesaria ante la abundancia de materias primas disponibles en la playa cercana. Las razones pueden ser múltiples, una posibilidad es la reutilización del asentamiento y el uso de las matrices disponibles en el mismo emplazamiento. Otra alternativa, es el uso simultáneo de una matriz para distintos fines, lo que permitiría desprender la intensidad de las actividades realizadas en esta(s) ocupación(es). No obstante, hay que considerar que éste es un contexto superficial y es difícil establecer o diferenciar eventos ocupacionales distintos.
En cuanto a la técnica empleada para la elaboración de la hendidura, en ambos sectores se observa un predominio de muescas por piqueteado en el borde del eje transversal y en la mayoría de los casos es muy poco insinuado. En un porcentaje más bajo se encuentran las muescas logradas por extracción y piqueteado, y escasamente representados los semisurcos. Sólo en el sector noreste se hallaron piezas con muescas profundas por extracción (Tabla 6).

En cuanto a las materias primas, la totalidad de pesas se encuentra manufacturada sobre guijarros, seguramente extraídos de la playa que se encuentra a unos metros del sitio. Si bien, se utilizaron guijarros de diversas materias primas, como basaltos (grano medio y compacto), granito (grano grueso y de baja a mediana compacidad) y otras no identificadas (de grano grueso y mediana compacidad); se puede observar una ligera asociación entre las pesas con atributos multifuncionales y matrices basálticas de grano medio y compacto (Tabla 7). Esta selección probablemente depende de la función de yunque o percutor, que requieren matrices de mayor resistencia y peso, especialmente en el caso del percutor. En el caso del granito y las rocas indeterminadas con baja a media densidad, se utilizaron principalmente para pesas de uso específico.

Tabla 6. Frecuencia de pesas según el tipo y técnica de modificación en ambos sectores de PC-3.

\begin{tabular}{|c|c|c|c|c|}
\hline \multirow{2}{*}{ Técnica y tipo de modificación } & \multicolumn{2}{|c|}{ sector noreste } & \multicolumn{2}{|c|}{ sector conchal } \\
\hline & Pieza & $\%$ & Pieza & $\%$ \\
\hline Extracción & 3 & 8,33 & & \\
\hline Extracción y piqueteado & 7 & 19,44 & 4 & 33,33 \\
\hline Piqueteado & 19 & 52,77 & 7 & 58,33 \\
\hline Semisurco & 7 & 19,44 & 1 & 8,33 \\
\hline Total & 36 & 100 & 12 & 100 \\
\hline
\end{tabular}


Tabla 7. Sitio Punta Catalina 3; sector conchal y sector noreste (NE). Frecuencia absoluta de piezas según su función y materia prima.

\begin{tabular}{lcccccccccccc}
\hline & \multicolumn{4}{c}{ Basalto } & \multicolumn{4}{c}{ Granito } & \multicolumn{5}{c}{ indeterminadas } \\
\hline \multicolumn{1}{c}{ Función } & conchal & NE & Total & $\%$ & conchal & NE & total & $\%$ & conchal & NE & total & $\%$ \\
\hline Pesa & & 3 & 3 & 37,5 & 1 & 10 & 11 & 78,5 & 6 & 19 & 25 & 96,1 \\
Pesa/per & 1 & 1 & 2 & 25 & 1 & & 1 & 7,1 & 1 & & 1 & 3,8 \\
Pesa/yun & & 1 & 1 & 12,5 & 1 & 1 & 2 & 14,2 & & & & \\
Pesa/yun/per & 1 & 1 & 2 & 25 & & & & & & & & \\
$\quad$ TOTAL & 2 & 6 & 8 & 100 & 3 & 11 & 14 & 100 & 7 & 19 & 26 & 100 \\
\hline
\end{tabular}

La elección de la matriz por morfología y tamaño da cuenta que la mayoría de las formas base son guijarros ovoidales y circulares, y en menor medida guijarros alargados y/o irregulares. También se puede percibir que hay diferencias en la función de las piezas. Las matrices circulares no se ocupan para un uso multifuncional, estas últimas sólo están hechas en piezas ovoidales. En cambio, las pesas de uso específico están elaboradas en distintas formas de matrices, aunque los guijarros circulares y aplanados se utilizan exclusivamente para este tipo de piezas. Estas observaciones pueden sugerir que la reutilización se hace sólo en piezas de formas determinadas, como son las ovoidales.

Por su parte, la selección de matrices según su sección, muestra que la mayoría de las piezas es de sección transversal plana/plana o plana/convexa, principalmente en las piezas de función específica. Por su parte, las pesas multifuncionales varían de plano/convexa a biconvexa y son preferentemente guijarros ovoidales. Las pesas de uso específico están hechas indistintamente en matrices circulares, ovoidales, alargadas e irregulares. No obstante, se constata que las piezas muy aplanadas, de morfología circular y con semisurco en el borde no se reutilizaron en otras funciones (Fig. 4).

Los atributos métricos muestran que en el sector noreste las piezas son relativamente más pequeñas en largo, ancho, espesor y peso, a su vez, presentan una desviación estándar menos significativa que las piezas del conchal. Este último, mostró ejemplares levemente más grandes y de mayor peso, no obstante, la cantidad de piezas de la muestra es más pequeña que la del primer sector. En cuanto al espesor de las piezas, en ambos sectores se mostró bastante estrecho con relación al ancho y largo; lo que se ajusta con el predominio de secciones plana/plana. Este atributo probablemente es un requisito importante en la elección de matrices. Una alternativa en esta preferencia es que las superficies planas permiten tener menos posibilidades de desplazarse y presentan mayor resistencia con el movimiento de la red y el oleaje; esto, a diferencia de las formas más redondeadas que pueden desplazarse más fácilmente.

En cuanto al peso de las piezas, en el sector noreste se concentran en el rango de los 400-600 grs y en menor medida en los 600-700 grs, en cambio, en el conchal predominan las pesas entre los 700-800 grs (Fig. 5).

En términos de la composición artefactual general de cada sector, el sector noreste muestra un predominio de pesas (55,2\%); no obstante, se observan instrumentos destinados a la fabricación de instrumentos, como percutores y yunques; instrumentos de faenamiento como raederas con la segunda mayoría (33,8\%), tajadores, cuchillos e instrumentos de raspado y desechos de boleadora.

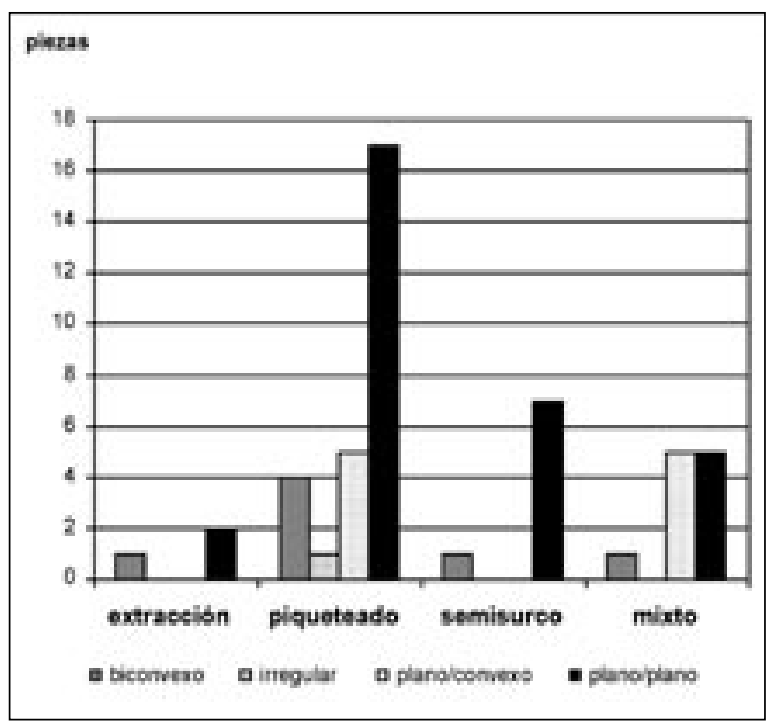

Fig. 4. Sitio Punta Catalina 3: Frecuencia absoluta de piezas según sección transversal $y$ tipo de modificación en el eje menor. 


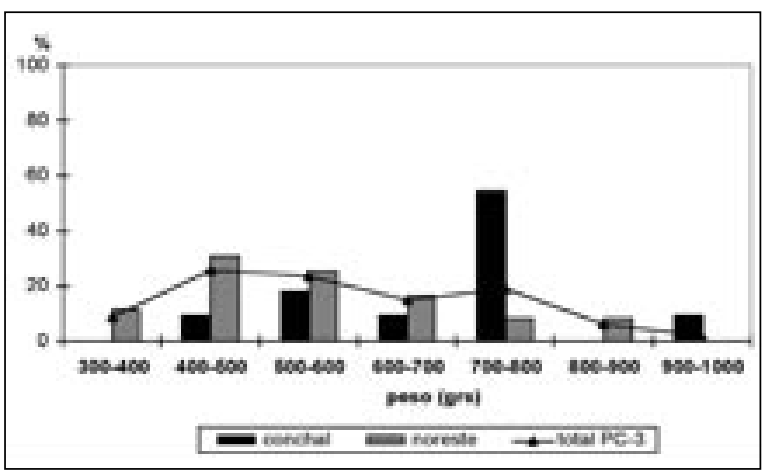

Fig. 5. Sitio Punta Catalina 3. Distribución de peso, por sector y en el sitio como unidad.

Esto indicaría la ejecución de tareas diversas en este sector del sitio, no obstante hay que considerar los procesos postdepositacionales (deflación de la duna, desplazamiento, escurrimiento de agua), que en este sector han actuado intensivamente redepositando los materiales. Ahora, si bien las pesas presentan un porcentaje bastante mayor, se debe tomar con moderación la importancia de esta actividad en comparación a las demás, ya que para el uso de una red se requiere de un conjunto de pesas, sumado a esto la baja inversión laboral y la disponibilidad de matrices idóneas, hacen que la tasa de descarte sea mayor que en otros artefactos. A diferencia del conjunto anterior, en el conchal los instrumentos de faenamiento predominan en la muestra, como raederas con el 51,8\%, cuchillos con un 7,2\%, tajadores con un $4,8 \%$, raspadores con un $14,4 \%$ y las pesas con sólo el 13,2\%.

Contextos de bahía Inútil; noroeste de Tierra del Fuego

En los conjuntos de bahía Inútil la mayoría de las piezas fue hallada en contextos superficiales, en agrupaciones acotadas, y en algunos casos sin asociación a otros materiales culturales y sin adscripción cultural ni cronológica (MA-30). No obstante, forman parte de un agregado o una continuidad de conchales y dispersiones de material óseo y lítico, algunas de éstas con fechados absolutos y adscritas a cazadores terrestres tardíos, como MA-38 y MA-32 (Massone et al. 2003).

\section{Sitio Marazzi 1 sector 4 y Marazzi 1B}

Son 6 piezas, 4 de granito; casi todas presentan sección biconvexa y con la modificación para el amarre en el eje menor. Las técnicas y tipos de modificaciones son muescas por extracción, por técnica mixta, y una variación respecto a los demás ejemplares, es el surco transversal completo con muescas laterales (Tabla 8, Fig. 6). En cuanto a

Tabla 8. Muestra de los sitios del sector de bahía Inútil.

\begin{tabular}{c|ccccc}
\hline Sitio & Materia Prima & morfología general & sección & ubicación & tipo y técnica de modificación \\
\hline \multirow{5}{*}{ MA-30 } & Granito & circular & biconvexo & eje menor & surco y refuerzo \\
& Granito & ovoidal & biconvexo & eje menor & surco y refuerzo \\
& Granito & ovoidal & biconvexo & eje menor & surco y refuerzo \\
& Granito & alargada & plano/plano & eje menor & surco y refuerzo \\
& Granito & circular & biconvexo & eje menor & surco y refuerzo \\
& Granito & circular & biconvexo & eje menor & surco y refuerzo \\
& Granito & ovoidal & biconvexo & eje menor & extracción y piqueteado \\
& Arenisca & ovoidal & plano/plano & eje menor & piqueteado \\
& Otras indet. & ovoidal & plano/plano & eje menor & piqueteado \\
& Otras indet. & ovoidal & plano/convexo & eje menor & piqueteado \\
& Granito & circular & biconvexo & eje menor & piqueteado \\
& Arenisca & ovoidal & plano/plano & eje menor & extracción y piqueteado \\
& Granito & ovoidal & biconvexo & eje menor & surco y refuerzo \\
MA-1/ & Granito & alargada & biconvexo & eje menor & surco y refuerzo \\
& Granito & ovoidal & biconvexo & eje menor & extracción y piqueteado \\
& Granito & ovoidal & biconvexo & eje menor & extracción y piqueteado \\
& Otras indet. & ovoidal & biconvexo & eje menor & extracción \\
\hline \multirow{2}{*}{ MA-1B } & Otras indet. & alargada & plano/plano & eje menor & piqueteado \\
\hline MA-32 & Otras indet. & alargada & plano/plano & eje menor &
\end{tabular}




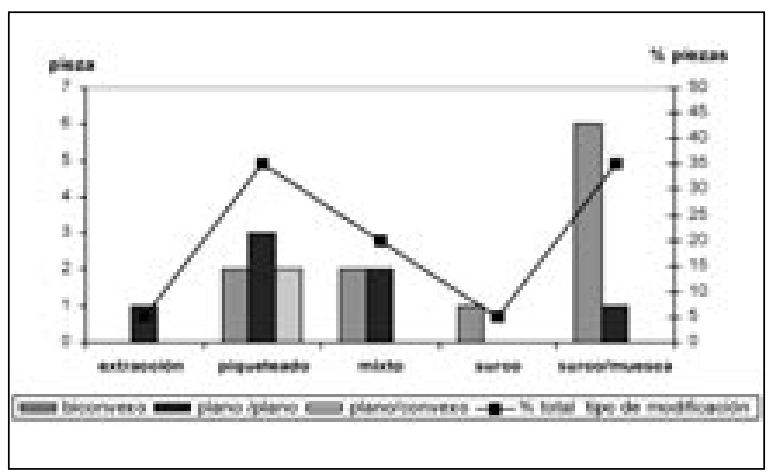

Fig. 6. Secciones y tipo de modificación del conjunto total del sector de bahía Inútil.

indicios de multifuncionalidad, en MA-1B se halló una pieza con atributos de peso/yunque/sobador.

\section{Marazzi 30 y MA-32}

En MA-30 hay 12 pesas que presentan modificaciones en su eje menor (Tabla 8, Figs. 6 y 7). En cuanto al tipo de modificación representada, la mitad de la muestra es de granito y presenta surco transversal continuo con refuerzo en el borde $y$ la otra mitad presenta muescas por piqueteado lateral no muy marcado y 1 sola con muescas por extracción y piqueteado, en este conjunto hay de granito, arenisca y otras indeterminadas. Hay secciones planas como biconvexas, destacando que la única tendencia es que las piezas con surco y muescas laterales tienden a ser biconvexas (Fig. 6). Una razón posible para la realización de surcos con muescas o refuerzos laterales al igual que en MA-1 sector 4 y MA-1B, es que la sección biconvexa de las piezas puede producir un desajuste del amarre al desplazarse la red, por tanto, se requiere de un mayor ajuste. En cuanto a los rasgos de multifuncionalidad, sólo 1 pieza muestra además su utilización como yunque.

Por otro lado, en MA-32 hay sólo una pieza y es el único ejemplar hallado en estratigrafía de los contextos de bahía Inútil. Es un guijarro de morfología alargada, sección plana y presenta muescas laterales por piqueteado suave.

\section{Muestra de referencia: Contextos Canoeros}

De 3 sitios vinculados a grupos de adaptación marina, se analizaron sólo 8 ejemplares (Tabla 9). Pese a lo pequeño del conjunto se puede observar

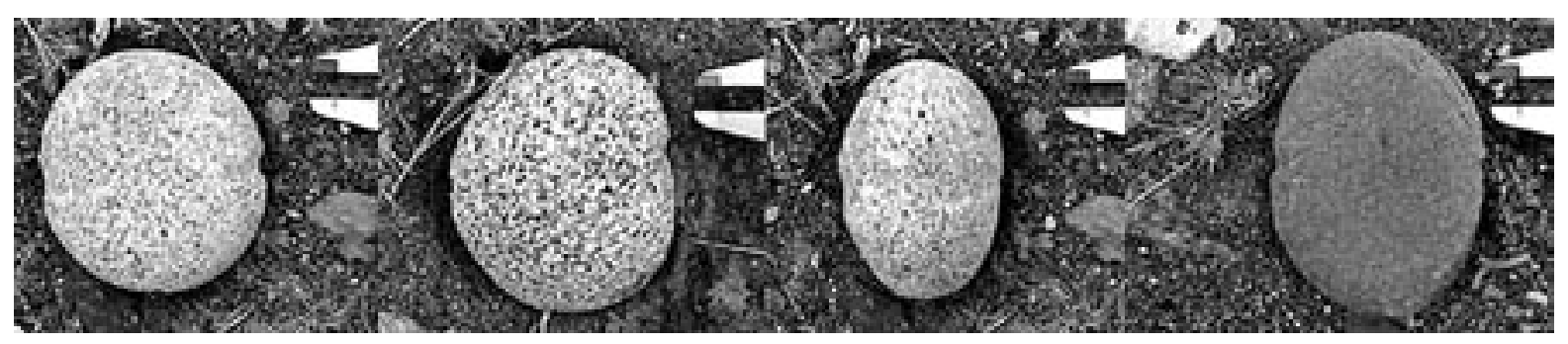

Fig. 7. Piezas de Marazzi 30, bahía Inútil.

Tabla 9. Muestra estudiadas de sitios canoeros.

\begin{tabular}{|c|c|c|c|c|c|c|c|}
\hline Piezas & morfología & Sección & ubicación & tipo de elaboración & Largo & Ancho & Espesor \\
\hline \multirow{2}{*}{ B. Buena 1} & ovoidal & biconvexo & eje mayor & \multirow{2}{*}{$\begin{array}{l}\text { semisurco } \\
\text { piqueteado/extracción }\end{array}$} & 7,4 & 6,64 & 3,4 \\
\hline & ovoidal & plano/plano & eje mayor & & 7,6 & 6,2 & 5,6 \\
\hline \multirow{3}{*}{ P. Carrera 1} & circular & plano/plano & $\begin{array}{l}\text { extremos } \\
\text { y } 1 \text { lateral }\end{array}$ & extracciones & 7,6 & 6,79 & 2,4 \\
\hline & circular & plano/plano & eje mayor & extracciones & 8,32 & 7,13 & 2,3 \\
\hline & ovoidal & biconvexo & extremos & semisurco/piqueteado & 9,37 & 8,23 & 4,6 \\
\hline \multirow{6}{*}{ Wulaia 15} & cuadrangular & biconvexo & eje mayor & semisurco & 3,89 & 3,43 & 2,9 \\
\hline & ovoidal & biconvexo & eje mayor & surco & 7,39 & frag. & 5,7 \\
\hline & ovoidal & plano/convexo & eje mayor & semisurco & 8,69 & 6,22 & 5,22 \\
\hline & & & & $\mathrm{x}$ : & 9,6 & 6,08 & 6,42 \\
\hline & & & & $\mathrm{ds}(1):$ & 7,76 & 6,34 & 4,28 \\
\hline & & & & $\mathrm{ds}(2)$ : & 1,67 & 1,36 & 1,55 \\
\hline
\end{tabular}



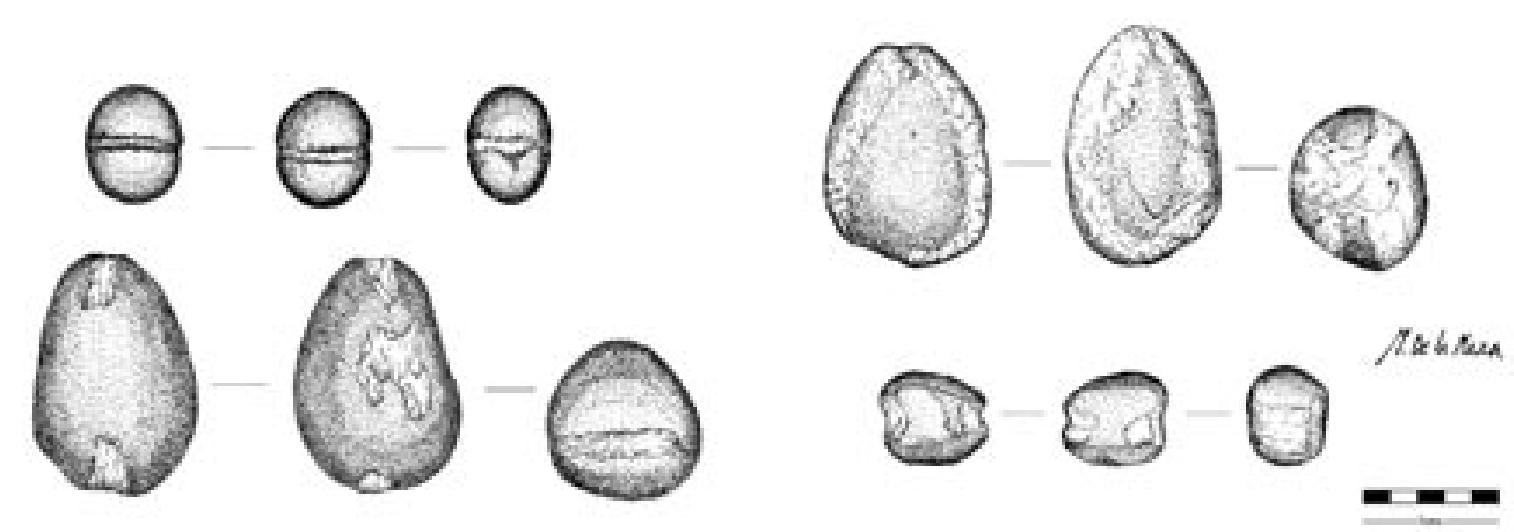

Fig. 8. Pesas líticas de Wulaia 15. Vista anverso, reverso y sección transversal de las piezas.

variabilidad en la sección de las piezas habiendo tanto de sección plano/plano como biconvexas en la misma proporción. No obstante, la morfología general es principalmente ovoidal, más que circular. Un rasgo que presenta alta similitud entre las piezas, es la ubicación de la modificación, en todos los casos observados se encuentra en el eje mayor de la pieza, es decir en el sentido longitudinal, $y$ el tipo de modificación más frecuente es el surco completo y el semisurco (Tabla 9 y Fig. 8). Destaca que la mayor variación registrada es el tamaño y peso de los ejemplares, oscilando entre $3,8 \mathrm{~cm}$ hasta 9,6 cm de largo (Tabla 9).

\section{DISCUSIÓN}

En cuanto a los resultados obtenidos se debe tomar en consideración las restricciones metodológicas que se presentaron. Primeramente, la mayor parte de las concentraciones de pesos del sector de bahía Inútil es superficial y presenta dificultades en su adscripción temporal y cultural; a excepción de MA-32, vinculado a cazadores terrestres tardíos (Massone et al. 2003). Ligado a esto, MA-30 no presenta asociación a otros elementos culturales y en MA-1B y MA-1/sector 4, los procesos de deflación del sector pueden haber ocasionado palimpsesto de los eventos ocupacionales. Pese a estos problemas, se observa que en general el conjunto de bahía Inútil, muestra características comunes; en general son concentraciones superficiales acotadas, a excepción de la pieza de MA-32. Junto a esto, la mayoría de los ejemplares es de granito, sección biconvexa y surco con refuerzo o sólo muescas, y en todos los casos los surcos se ubican en el eje transversal de la pieza.

Por otro lado, PC-3 y PB-7 del noreste de Tierra del Fuego presentan mayor resolución respecto a la temporalidad del contexto y a su adscripción cultural, señalando que ambos se vinculan a cazadores terrestres tardíos. Se destaca que en PC-3, una pieza fue encontrada en estratigrafía y asociada a un predominio de fauna ictiológica en comparación a la demás fauna vertebrada -a partir del NISP [número mínimo de especímenes] y el MNI [número mínimo de individuos]-, y representada casi exclusivamente por Eleginops maclovinus (Massone y Torres 2004). Es necesario considerar que tanto en PC-3 como los conjuntos de bahía Inútil son concentraciones de pesos dispersos en un área delimitada, similar a algunos conjuntos de pesas de red de otras áreas (Bustos y Vergara 1998, Greenspan 1998).

Por su parte, el conjunto de PC-3 exhibió un predominio de secciones aplanadas y sin una tendencia marcada hacia el uso de granito, a diferencia del conjunto de bahía Inútil; no obstante, se observa el traslape de la dispersión del largo y ancho de ambos conjuntos (Fig. 9). Sin embargo, en PC-3 se distingue una agrupación de piezas con largo y ancho proporcional, lo que se traduce en piezas de morfología semicircular de sección plana, exclusivas de este contexto. Por otro lado, los sitios canoeros muestran una dispersión de tamaños que se encuentra por debajo de los ejemplares arriba mencionados, aunque no menor a los de PB-7, que presenta los tamaños más bajos.

El rasgo más destacado en todos los conjuntos del norte de Tierra del Fuego, es la ubicación del 


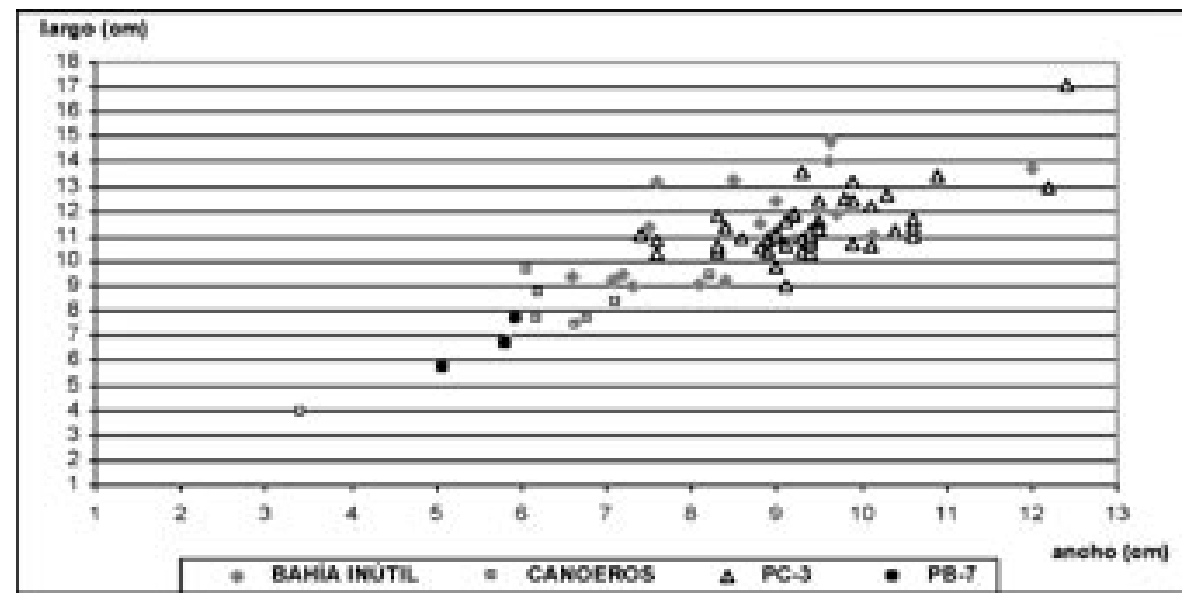

Fig. 9. Dispersión de los tamaños de las piezas en los distintos conjuntos estudiados.

surco, semisurco o muesca que siempre se realizó en el eje transversal de la pieza, no así en los conjuntos canoeros, que en todos los casos la modificación se situó en el eje longitudinal. Junto con esto, los conjuntos canoeros presentan alta variabilidad en los tamaños, pesos, técnica y tipo de modificación. No obstante, existe un predominio de secciones biconvexas y en todos los casos las modificaciones se dan en el eje longitudinal.

Con relación al peso, los ejemplares del norte de Tierra del Fuego, presentan una amplia distribución entre los 200 y 900 grs, y se concentran entre los 400 y 600 grs. Por su parte, los conjuntos canoeros se dispersan en rangos de peso menores, entre los 100 y 400 grs, y que no sobrepasan los 650 grs (Fig. 10).

En síntesis, pese a la variación interna de los conjuntos asignados a canoeros y los del norte de Tierra del Fuego asignados a cazadores terrestres; se distinguen diferencias en el rango de peso, rango de tamaño, ubicación de la modificación y tendencia en las secciones entre estos conjuntos.

$\mathrm{Si}$ consideramos que las diferencias en los atributos morfológicos y métricos son reflejo de métodos de pesca distintos, se debe tomar en cuenta que en el caso de los pesos de red la distribución de peso y tamaño puede variar en función de dónde y cómo se utilizó la red, incluso hay redes que no requieren de pesos para ejecutarla, como se sugiere para la red que los selk'nam usaban en los ríos (Gallardo 1998). De igual manera, en PB-7 pese a que la mayoría de las pesas es de menor tamaño que las demás del norte de Tierra del Fuego, igual presenta la modificación en su eje transversal, como todas las piezas del norte de Tierra del Fuego.

Por lo pronto, podemos plantear que los pesos líticos del norte de Tierra del Fuego presentan atributos tecnológicos y características contextuales similares a los pesos para red de otras áreas. Por el momento estos conjuntos son vinculables a ocupaciones de

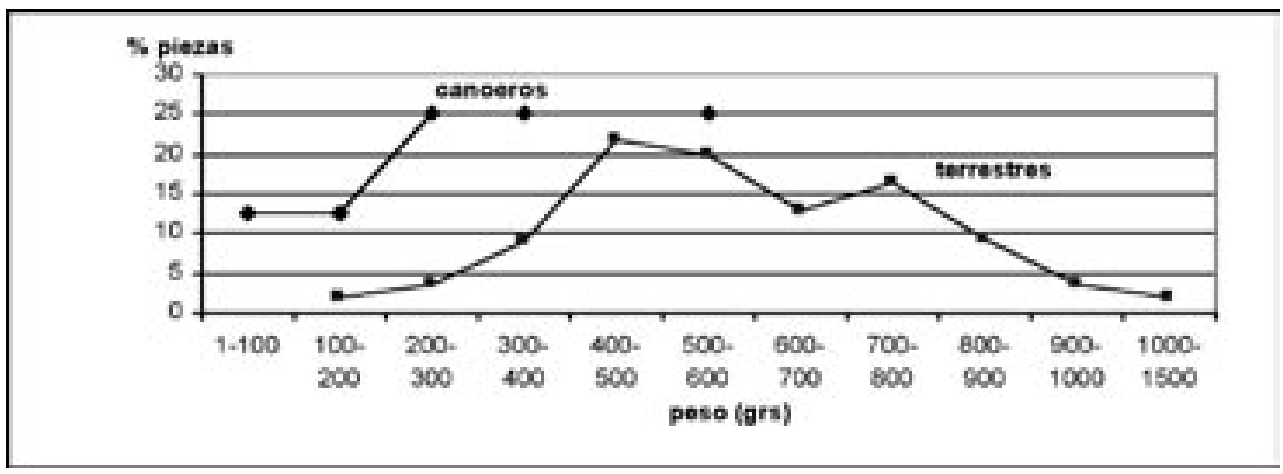

Fig. 10. Comparación entre la distribución de peso de los conjuntos canoeros y terrestres. 
cazadores terrestres tardíos, lo que podría indicar que el uso de este artefacto complementario a la red de pesca fue abandonado en momentos de contacto europeo o que simplemente no fue observado y registrado etnográficamente. Por el contrario, si se considera que las piezas de los contextos asignados a canoeros tempranos son pesos de línea por su semejanza a los pesos descritos etnográficamente, $y$ por algunos atributos similares a los de otras áreas; se puede desprender la persistencia de un aspecto de la estrategia de subsistencia general de estos grupos, como ya se ha mencionado con anterioridad (Orquera y Piana 1999b).

En este caso puntual se da la relación entre un método de pesca y un grupo cultural determinado, no obstante, se ha reportado que los selk'nam utilizaron cebo o líneas de pesca sin mención del uso de pesos; por lo que no se descarta que hubieran usado pesos o que sus antecesores los hayan utilizado. De esta manera podemos sugerir que los pesos más pequeños de PB-7 podrían haber servido para estos fines, no obstante, no se asemejan en nada a los pesos de línea registrados en contextos canoeros.

\section{CONCLUSIONES}

El bajo valor diagnóstico de algunos artefactos puede ser potenciado con un enfoque metodológico que integre elementos de analogía etnográfica del área cultural y de otras áreas alejadas, además de la información contextual de cada caso analizado. Sin embargo, es necesario tomar esto con reserva, ya que se basa en la idea que los requerimientos técnicos y tecnológicos de un instrumento de función determinada pueden ser semejantes a la de instrumentos de áreas y períodos distintos; esto se debe contemplar, no sin antes considerar los aspectos culturales y ambientales particulares en los que se ubican estos conjuntos, que inciden en la variabilidad y dificulta una simple extrapolación.

Por consiguiente se plantea que los cazadores terrestres del norte de Tierra del Fuego utilizaron redes de pesca complementándolas con pesos, por tanto, la técnica pudo ser similar a la utilizada en redes de trasmallo. Esta técnica pudo haber sido abandonada en momentos tardíos por lo que no fue registrada etnográficamente. Tal situación pudo ocurrir con el uso de la boleadora por los selk'nam (Gusinde 1982). No obstante faltan más datos para precisar esto como fechados absolutos, asociación de estas piezas a contextos estratigráficos y su relación a la estructura de los conjuntos ictioarqueológicos.

\section{AGRADECIMIENTOS}

Agradezco de forma muy particular a Mauricio Massone por permitirme desarrollar este trabajo en el marco del proyecto FONDECYT 1020004. De igual modo, extiendo mis agradecimientos a Donald Jackson, Flavia Morello, Nicolás Lira y Marcela Lucero por revisar secciones de este trabajo y realizarme valiosas observaciones y sugerencias; a Magdalena De la Maza por su colaboración en la realización de las ilustraciones; y a Florence Constantinescu, Pedro Cárdenas, Ismael Martínez, Alfredo Prieto y Manuel San Román por facilitarme el acceso a las colecciones arqueológicas y por aportar datos e ideas para el desarrollo de este trabajo.

\section{BIBLIOGRAFÍA}

ÁlVAREZ, M. 2004. Estrategias tecnológicas en los grupos canoeros tempranos del área Fuego-Patagónica. Magallania 32:191-208. Punta Arenas.

ASCHERO, C. 1983 (1975). Ensayo para una clasificación morfológica de artefactos líticos aplicada a estudios tipológicos comparativos. Informe CONICET MS.

BANK, T. 1953. Cultural Succesion in the Aleutians. American Antiquity 19[1]:40-49.

BRIDGES, L. 2000 (1947). El último confín de la tierra. Editorial EMECÉ. Buenos Aires.

BUSTOS, V. y N. VERGARA. 1998. El Visal y Talcahuano 1 , ejemplos de sedentarismo y especialización en el arcaico tardío del litoral de la VIII Región. Concepción, Universidad San Sebastián, Serie Antropología [Actas 1er Seminario de Arqueología, zona centro-sur de Chile], 1:65-74.

CLEYET-MERLE, J. J. 1990. La Préhistoire de la peche, Collection des Hesperides, Errance, Paris.

CONSTANTINESCU, F., I. MARTÍNEZ y V. SANZ. 2005. "Informe final caracterización arqueológica proyecto parque arqueológico caleta Wulaia, empresa de transportes marítimos Terra Australis S.A." C.E.H.A. Instituto de la Patagonia, Universidad de Magallanes.

CONTRERAS, L. y J. JACKSON. 2004. Análisis del Conjunto Lítico del Sitio Playa Negra 9. En: Resultados de Análisis, 
Interpretaciones y Conclusiones del Material Cultural, Ecofactual y Bioantropológico del Sitio Playa Negra 9. Comuna de Penco, VIII Región del Bío Bío. Rescate Arqueológico Obra Ruta Interportuaria Talcahuano-Penco. Constructora Besalco. Investigadora Responsable: Claudia Silva Díaz.

COIAZZI, A. 1997 (1914). Los indios del archipiélago fueguino. Editorial Ateli, Punta Arenas.

CHAPMAN, A. 1982. Drama and power in a hunting society: the Selk'nam of Tierra del Fuego. Cambridge: Cambridge University Press.

- 1989. El fin de un mundo. Los Selk'nam de Tierra del Fuego. Vásquez Manzini Editores. Buenos Aires.

EMPERAIRE, J. 1963. Los nómadas del mar. Ediciones de la Universidad de Chile. Santiago.

EMPERAIRE J. y A. LAMING. 1961. Les gisements des îles Englefield et Vivian. Journal de la Société des Américanistes 50:7-75.

GALLARDO, C. 1998 (1910). Tierra del Fuego. Los onas. Cabaut y Cía., Buenos Aires.

GONZÁLEZ, R. 1953. Las boleadoras, sus áreas de dispersión y tipos. Revista del Museo de la Universidad Nacional de La Plata (entonces Eva Perón). Sección antropología. La Plata.

GREENSPAN R. L. 1998. Gear selectivity models, mortality profiles and the interpretation of archaeological fish remains: A case study from the Harney basin, Oregon. Journal of Archaeological Science 25:973-984.

GUSINDE, M. 1937. Die Feverland-Indianer: Bd. 2: Die Yamana. Von Leben and Denken der wasser nomaden am Kap Horn. Verlag Anthropos, Mödling.

- 1982. Los indios de Tierra del Fuego. Los Selk'nam. Centro Argentino de Etnología Americana, Buenos Aires.

HENSHAW, W. 1885. The aboriginal relics called sinkers or plummets. American Journal of Archaeology 1[2]:105-115.

LANATA, J. L. 1996. The "haush" puzzle: piecing together subsistence and settlement at the fueguian southeast. Revista do Museu de Arqueologia e Etnologia, Sao Paulo. 6:11-32.

LEGOUPIL, D. 1997. Bahía Colorada (île d'Englefield). Les premiers chasseurs de mammifères marins de Patagonie australe. Mémoires de l'A.D.P.F., Recherches sur les Civilisations, Paris.

LISTA, R. 1998 (1887). Viaje al país de los onas, Tierra del Fuego. Alberto Núñez [reed]. En: Obras. Buenos Aires. Confluencia, vol. 2:9-118.
LOTHROP, S. 1928. The Indians of Tierra del Fuego. Contributions of the Museum of the American Indian, Heye Foundation, 244 pp. New York.

MASSONE, M. 1997. Prospección Arqueológica del sector comprendido entre río Marazzi y Torcido, Zona Norte de Tierra del Fuego. Anales del Instituto de la Patagonia. Serie Ciencias Sociales 25:123-136. Punta Arenas.

MASSONE, M., F. MORELLO, A. PRIETO, M. SAN ROMÁN, F. MARTÍN y P. CÁRDENAS. 2003. Sitios arqueológicos, restos de cetáceos y territorios locales selk'nam en Bahía Inútil, Tierra del Fuego. Magallania, 31:45-59, Punta Arenas.

MASSONE, M. y J. TORRES. 2004. Pesas, peces y restos de cetáceos en el campamento de Punta Catalina 3 (2.300 años AP.). Magallania, Punta Arenas.

MASSONE, M. y F. MORELLO. 2005. Los cetáceos en el mundo selk'nam, estudios arqueológicos. Informe final, proyecto FONDECYT 1020004.

MORELLO, F. 1999. Cazadores terrestres del Holoceno Medio y Temprano en Tierra del Fuego: Marazzi 1, una discusión abierta. Tesis para optar al grado profesional de arqueólogo. Universidad de Chile. Santiago, Chile.

MORELLO, F. 2000. 30 años después, una primera aproximación a la colección Marazzi (Museo Regional Punta Arenas). Actas de las Cuartas Jornadas de Arqueología de la Patagonia, Tomo II: 481-497.

MORELLO, F., L. CONTRERAS y M. SAN ROMÁN. 1999. La localidad de Marazzi y el sitio arqueológico Marazzi I, Una re-evaluación. Anales del Instituto de la Patagonia. Serie Ciencias Sociales 27:187-197. Punta Arenas.

MORELLO, F., L. CONTRERAS, M. SAN RÓMAN, I. MARTÍNEZ, F. MARTIN y M. BAHAMONDES. 2005. El sitio Punta Baxa 7, Primera Angostura Tierra del Fuego. Informe de avance último año, proyecto FONDECYT 1020004.

OCAMPO, C. y P. RIVAS. 1996. Caracterización Arqueológica preeliminar del suroeste de Tierra del Fuego. Anales del Instituto de la Patagonia Serie Ciencias Sociales 24:125-151.

ORQUERA, L.A. y E.L. PIANA. 1986. Normas para la descripción de objetos arqueológicos de piedra tallada. CADIC, Argentina.

ORQUERA, L. y E. PIANA. 1999a. La vida material y social de los yámana. Buenos Aires: EUDEBA.

ORQUERA, L. y E. PIANA. 1999b. Arqueología de la Región del Canal Beagle (Tierra del Fuego, República Argentina). Sociedad Argentina de Antropología, 146 págs., Buenos Aires. 
ORQUERA, L. y E. PIANA. 2000. Imiwaia I: Un sitio temprano de canoeros del sexto milenio A.P. en la costa norte del canal Beagle. Actas de las Cuartas Jornadas de Arqueología de la Patagonia, Tomo II: 441-453.

ORTIZ-TRONCOSO, O. 1973. Aspectos arqueológicos de la Península de Brunswick (Patagonia Austral). Anales del Instituto de la Patagonia 4:109-129. Punta Arenas.

ORTIZ-TRONCOSO, O. 1975. Los yacimientos de Punta Santa Ana y Bahía Buena (Patagonia Austral): excavaciones y fechados radiocarbónicos. Anales del Instituto de la Patagonia 6:93-122. Punta Arenas.

ORTIZ-TRONCOSO, O. 1978. Punta Santa Ana et Bahía Buena: deux gisements sur une ancienne ligne de rivage dans le Détroit de Magellan. Journal de la Société des Américanistes 56:133-204.

PENNYPAKER, S. 1938. The problem of the "Plummet-stone". American Antiquity 4[2]:142-146.

PIANA, E. L., J. ESTÉVEZ ESCALERA, y A. VILA MITJÁ. 2000. Lanashuaia: Un sitio de canoeros del siglo pasado en la costa norte del canal de Beagle. En: Desde el País de los Gigantes: perspectiva arqueológica en Patagonia, Tomo II. Pp:455-469. Universidad Nacional de la Patagonia Austral. Río Gallegos.

PRIETO, A. 2004. Redes para peces y trampas para aves: El caso selk'nam de la Tierra del Fuego. Informe de avance segundo año, proyecto FONDECYT 1020004. Ms.

PRIETO, A. y R. CÁRDENAS. 2002. Las Colecciones etnográficas fuego/patagónicas en los museos europeos. Anales del Instituto de la Patagonia. Serie Ciencias Humanas 30:65-77, Punta Arenas.
QUIROZ, D., M. SÁNCHEZ y M. MASSONE. 2001. Co-3: poblamiento temprano en las costas de Arauco. Boletín de la Sociedad Chilena de Arqueología, 32.

SCHINDLER, H. 1995. Un informe etnográfico sobre los onas del año 1765. Runa XXII: 177-185.

SEGUEL, Z. 1998. El conchal Bellavista 1 y el poblamiento temprano en el sector litoral de la bahía de Concepción. Actas 1er Seminario de Arqueología, zona centro-sur de Chile. Concepción, Universidad San Sebastián: 25-40.

TORRES, J. 2004. Estrategias de pesca utilizadas por los selk'nam del norte de Tierra del Fuego: evaluación de antecedentes etnográficos y datos arqueológicos de bahía Inútil. Informe de avance segundo año. Ms.

- 2005. Hacia una zooarqueología de los recursos ictiológicos en Tierra del Fuego: Un caso de estudio en contextos arqueológicos selk'nam de bahía Inútil. Actas XVI Congreso Nacional de Arqueología Chilena. Tomé. En prensa.

TORRES, J., C. SILVA y M. LUCERO. 2007. El rol de la pesca en la intensificación de las ocupaciones costeras durante el Holoceno Medio-Tardío (Bahía de Concepción, Región del Bío-Bío, Chile). Magallania 35(1):115-138, Instituto de la Patagonia, Punta Arenas.

TUOHY, D. 1968. Stone sinkers from western Nevada. American Antiquity 33[2]:211-215.

ZANGRANDO, A. F. 2003. Ictioarqueología del canal Beagle, explotación de peces y su implicación en la subsistencia humana. Sociedad Argentina de Antropología, Colección Tesis de Licenciatura. Buenos Aires. 